\title{
The art of medicine
}

Punitive social policy: an upstream determinant of health

"I will be sending a man to prison for asking for food when he was hungry" a UK judge professed before sentencing a homeless person to 4 months of jail for persistent begging. This is not an isolated incident. Across Europe, growing numbers of vulnerable people are targeted by public authorities for so-called antisocial behaviour, including a seemingly irrepressible yet inexplicable urge to sleep on pavements rather than beds, or to engage in open displays of material hardship

Such "behaviour" and its punitive treatment by the state is the symptom of a broader political dynamic. In post-recession Europe, one aspect of this dynamic has enjoyed much attention, namely fiscal austerity, the harmful health effects of which have been well established. Such conclusion is part of an emergent scientific literature that examines how macro-level political and economic forces exert powerful effects on population health. But there is something else that seems to have escaped attention. Alongside welfare retrenchment, we should also consider the effect on population health of disciplinary laws and policies whereby instabilities wrought by economic decline are curbed and controlled. Punitive social policy combines the dismantling of the welfare state with the expansion of the penal state and its institutional correlates. It is associated with the regulation of poverty and of social division in the wake of political or economic shocks, such as recessions, industrial decline, or deepening inequalities. Punitive social policy also reflects the shifting concerns of the state from offering social support for the poor to suppressing their inconvenient yet conspicuous presence in the public sphere.

A blueprint of this pattern is seen in recent American history, where rising income gaps between the top and the bottom of the socioeconomic order have been accompanied by reduced welfare support for the most disadvantaged. From 1970 to 1996 , benefits for poor families with children had fallen by more than $40 \%$ in real terms in most states. For example, median monthly Aid to Families with Dependent Children (AFDC) welfare payments to poor single mothers plummeted from \$221 in 1970 to $\$ 119$ in 1995 , measured 
in constant dollars, which is equivalent to a net decline of over 50\% in purchasing power. Since the 1996 welfare reform introduced under former US President Bill Clinton, analogous to ongoing transformations of the British welfare state, social transfers have tumbled by at least another $20 \%$, to the point where, as of July, 2016, Temporary Assistance for Needy Families benefits for a family of three without any other income were under half of the official poverty line in every US state. In most states, benefits were less than $30 \%$ of the poverty line.

At the same time, since the early 1970s, incarceration in the USA has skyrocketed to reach a peak of almost eight inmates per 1000 residents, with an absolute number of more than $2 \cdot 3$ million people behind bars at its peak, which equates to a sevenfold increase in around four decades. The total correctional population, which includes those on probation and parole, largely drawn from the lower socioeconomic and non-white populations, has come to reach just under 7 million people. This punitive upsurge is not a unilinear function of crime, since rates of incarceration are more than three times higher in places of concentrated disadvantage[define do you mean poverty?] than in communities with similar crime rates. In 1972, the percentage of African American men below age 40 with no more than 12 years of completed education behind bars equalled roughly $4 \%$. By 2010 , this number had more than quadrupled to reach nearly $18 \%$. For European Americans, the incarceration rate jumped from around $1 \%$ to roughly $4 \%$ for those with at most a high school diploma in the same time period. If we look only at those who never completed their high school education, the figure went from $12 \%$ to $35 \%$ for African Americans and from $2 \%$ to around $13 \%$ for European Americans. In contrast, for those with at least some college education, incarceration rates remained virtually unchanged in both groups (at around $2 \%$ and $0.5 \%$, respectively). Comparing birth cohorts of individuals born in 1945-49, on the one hand, with those born in 1975-79, on the other, estimated probabilities of imprisonment over the life course reveal that, for those without a high school diploma, the cumulative risk of incarceration has risen from $4 \%$ to just below $30 \%$ for European Americans and from around $15 \%$ to more than $60 \%$ for African Americans. 
How do these developments relate to inequalities in health and wellbeing? The 2010 Marmot Review in the UK, offered_six policy recommendations: give each child the best start in life; enable people to maximise their capabilities and have control over their lives; create a fair work environment for all; ensure healthy living standards for all; create and develop healthy and sustainable communities; and strengthen the role and impact of ill-health prevention. But punitive social policy works against each of these recommendations by compounding the consequences of economic decline for health inequalities. In the USA, former inmates are mired in low-wage, precarious jobs if not chronic unemployment, and have

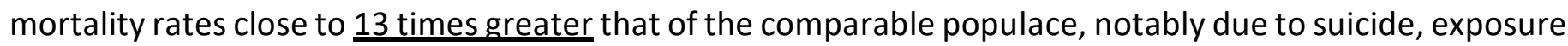
to neighbourhood violence, and the development of stress-related diseases. For a single mother struggling to make ends meet while her partner completes his sentence behind bars, eviction constitutes a consequential form of social relegation, leading to an inability to secure decent housing for her family, further downward mobility, and heightened risk of homelessness. In fact, in US poverty-stricken neighbourhoods with stagnating incomes and rising housing costs, eviction is to women wat incarceration is tomen. It follows from this that punitive social policy is an upstream determinant of adverse childhood experiences: its dire transgenerational effects are illustrated by how children with an incarcerated parent have a heightened likelihood of dropping out of school, developing learning disabilities[is this certain could omit?], becoming homeless, and suffering from a range of health problems. The fact that the cumulative risk of experiencing parental incarceration by age 14 among African American children born to high-school dropouts exceeds $50 \%$, conveys the magnitude of this social, political, and public health phenomenon. Eviction, downward household mobility, and ensuing unstable social relationships aggravate childhood exposures to adverse events that actively shape life-course trajectories and disease susceptibility.

Moreover, just as austerity has regionally differentiated effects in Europe, select urban landscapes have atrophied under the weight of the criminal justice system in the USA, which has extirpated prime age men from their neighbourhoods, torn families apart, disrupted social networks, and trapped local communities in vicious cycles of economic decline, violence, civic distress, and further punitive treatment by the state. In such a climate, public health interventions, where they are not pre-emptively scrapped through welfare 
cuts, will fail to eliminate inequalities in health unless they address and redress their upstream determinants. In other words, why treat people and send them back to the conditions that made them sick?

Is this all an American peculiarity? Welfare retrenchment is certainly not: in the wake of stringent fiscal austerity, population health has taken a blow in post-recession Europe. Budgetary belt-tightening has eroded health systems, precipitated infectious disease outbreaks, and rendered the social patterning of health and illness more pronounced. Neither is penal expansion an American singularity. Although nowhere near the USA in absolute levels-and notwithstanding non-custodial sentences-European prisons are at the edge of their capacity: just short of $30 \%$ of prison administrations experience overcrowding, and since 2009, European prison density has remained close to $100 \%$. In England and Wales, the prison system has been overcrowded every year since 1994 and the prison population has risen by $82 \%$ in the past three decades. Across Europe, political pressures on the welfare state have been accompanied by the punitive treatment of those tethered to the bottom rungs of the socioeconomic order-notably, post-colonial migrants and their descendants, whose disproportionate presence in European prisons echoes that of African Americans across the Atlantic.

For researchers and policy makers in public health and beyond, it is urgent that we adopt a multidimensional understanding of inequalities and their upstream determinants: the "causes of the causes" of ill health do not operate in isolation from one another and they tend to be mutually shaped at the intersection of powerful political and economic forces. To reverse the durable effects of punitive social policy, it is therefore insufficient to act on one health determinant at a time, even if that health determinant is causing major damage on its own. For instance, ending hyper-incarceration is unlikely to help society's most vulnerable unless the prison is viewed in tandem with other major societal institutions, including schools, labour markets, and health and social care systems. Achieving health equity is predicated on nothing less than a firm commitment to social justice.

\section{*Elias Nosrati, Michael Marmot}


Merton College, University of Oxford, Oxford OX1 4JD, UK (EN); and Institute of Health Equity, Department of Epidemiology and Public Health, University College London, UK (MM)

elias.nosrati@merton.ox.ac.uk [correct address and email?] 